\title{
DIRECT DISCRIMINATION WITHOUT A COMPARATOR? MOVING TO A TEST OF UNFAVOURABLE TREATMENT
}

\section{Colin Campbell** \&ale Smith ${ }^{\dagger}$}

\section{Introduction}

Traditionally, statutory provisions prohibiting direct discrimination have employed the notion of 'less favourable treatment'. This notion is a relative one; a person cannot be treated less favourably in the abstract, but only by comparison with the treatment accorded to somebody else. Thus, by employing the notion of less favourable treatment, statutory prohibitions on direct discrimination have traditionally required recourse to be made to a comparator. That is, the complainant has had to show that they were treated less favourably, by virtue of their possession of a protected attribute, than someone who did not possess the protected attribute, but who was otherwise in substantially the same circumstances as the complainant, was or would have been treated.

The use of a test of less favourable treatment has, however, been subject to significant criticism. The requirement that recourse be made to a comparator raises a number of difficulties. For example, in many cases, it is difficult to determine what is required to place a comparator (who does not have the protected attribute) in substantially the same circumstances as the complainant (who does have the protected attribute), whilst avoiding offensive or otherwise undesirable results. ${ }^{1}$ Furthermore, even if recourse can be made to a hypothetical comparator (as is the case in Australia), it may be difficult to ascertain how the

\footnotetext{
* Faculty of Law, Monash University.

$\dagger$ Melbourne Law School, University of Melbourne; Adjunct Senior Research Fellow, Faculty of Law, Monash University. We are grateful to Matthew Conaglen for very helpful comments on an earlier draft of this article. We are also very grateful to Sarah Holloway, Sam Szoke-Burke and David O'Loughlin for their excellent research assistance. Finally, we would like to thank two anonymous referees for their very helpful comments. ${ }^{1}$ The classic example concerns discrimination on the basis of the complainant's pregnancy. Initially, claims of this sort could not be made out, on the basis that men were unable to become pregnant and so there was no available comparator: see Turley v Allders Stores [1980] ICR 66, 70 (Bristow J). Later courts found a comparator, but only by comparing the complainant to a sick male: see, for instance, Webb $v E M O$ [1992] 2 All ER 43, 52 (Glidewell LJ). Interestingly, the UK has sought to eliminate the need to use a comparator in this context: see Equality Act 2010 (UK), s 18. By contrast, recent Australian case law seeks to characterise the comparator in gender neutral terms: see, e.g., Thomson v Orica Australia Pty Ltd (2002) 116 IR 186, 216-7. But there remain indications, in some cases, that the complainant is being compared to an employee who is sick: see, e.g., Ho v Regulator Australia Pty Ltd [2004] FMCA 62, [155] (though of Howe v Qantas Airways Ltd (2004) 188 FLR 1, 62).
} 
alleged discriminator would have treated that (hypothetical) comparator. ${ }^{2}$ Perhaps most fundamentally, it has been argued that assessing the complaint of a member of a disadvantaged group, by comparing the treatment they have received with that which was or would be received by a member of a privileged group, reinforces the privileged status of that latter group, by treating its members as the norm by reference to which the treatment accorded to members of the disadvantaged group is judged. ${ }^{3}$

There is, however, an alternative to the test of less favourable treatment - namely, a test of unfavourable treatment, such that the complainant must instead show that she was treated unfavourably by virtue of her possession of a protected attribute. ${ }^{4}$ As we shall see in Part I, there is a widely held view - one to which effect has sought to be given in actual and proposed legislation in several jurisdictions - that moving to a test of unfavourable treatment will eliminate the need to use a comparator at this stage of the determination of a claim in direct discrimination. (Henceforth, we will refer to the requirement that the complainant demonstrate that she was treated 'less favourably', or 'unfavourably', as the harm element in the claim in direct discrimination. The contrast is with the causation element, which requires the complainant to demonstrate that the treatment was accorded because of, or by reason of, her protected attribute.) The hope is that, by eliminating the need to rely on a comparator for the purposes of the harm element, the problems to which reliance on a comparator gives rise will also be eliminated.

\footnotetext{
${ }^{2}$ Consider, for example, an industry or workplace where the (non-managerial) employees are all female. It is often pointed out that this makes it difficult to find an actual comparator (see eg Sandra Fredman,

Discrimination Law (Clarendon Press, $\left.2^{\text {nd }} e d, 2011\right)$ 158.) However, a similar problem may arise with regard to hypothetical comparators. The very absence of male workers in the relevant workplace or industry, in anything like a comparable position, may make it difficult to determine how a hypothetical male comparator would have been treated.

${ }^{3}$ Thus, it is often objected that the use of a comparator results in a female complainant's claim being assessed by reference to a male standard or norm: see, e.g., Catherine McKinnon, Feminism Unmodified (Harvard University Press, 1987) 34. A similar point can be made with reference to, say, disability. It has been argued that there is a diverse range of abilities among different members of society, and disabled people should not be regarded as falling outside of that range. Indeed, it has been contended that a person is disabled only to the extent that society refuses to accommodate their abilities, while accommodating the abilities of other, differently abled people: see, e.g., Fredman, above n 2, 172. Yet assessing the treatment that a disabled person has received by reference to the treatment accorded to a person who is not disabled treats the non-disabled person as the norm by reference to which the disabled person is judged.

${ }^{4}$ Another possibility is to avoid using a general test of either less favourable or unfavourable treatment entirely, and instead to provide an exhaustive list of the actions which, if performed because of a protected attribute, will amount to unlawful discrimination. (Arguably, ss 342 and 351 of the Fair Work Act 2009 (Cth) establish such a scheme.) The merits and demerits of this approach fall outside the scope of this article; as we go on to explain in the text, our concern is with whether replacing a test of less favourable treatment with a test of unfavourable treatment eliminates the need to consider a comparator.
} 
The overarching aim of this article is to investigate, in greater detail than has hitherto occurred, whether using a test of unfavourable treatment obviates the need to rely on a comparator for the purposes of determining whether the harm element is made out. To avoid misunderstanding, we should emphasize that we accept that the problems to which reliance on a comparator gives rise are serious; our concern is with whether the need to use a comparator can, in fact, be avoided by employing a test of 'unfavourable treatment'.

To that end, we begin, in Part I, by presenting in greater detail the view that the need to use a comparator can be avoided in this way. Then, in Part II, we show that ascertaining whether that view is correct is a far from straightforward exercise. There is an influential approach to understanding the test of unfavourable treatment, which we call the 'setback to interests' approach, and which does obviate the need to rely on a comparator. However, we argue that this approach renders the test of unfavourable treatment over-inclusive in ways that Parliament would not have intended.

Having shown this, we proceed, in Parts III and IV, to consider two alternative approaches to understanding the test of unfavourable treatment. In Part III, we discuss the 'reasonable expectations' approach, according to which the question of whether treatment is unfavourable turns on the complainant's reasonable expectations. We argue that, while this approach avoids the over-inclusiveness problem that confronts the setback to interests approach, it either fails to eliminate the need to rely on a comparator or else collapses into the second alternative approach, which we consider in Part IV.

This second alternative approach is the 'value-based' approach, according to which the proper understanding of the test of unfavourable treatment is responsive to the value underlying prohibitions on discrimination. In Part IV, we argue that this approach also avoids the over-inclusiveness problem. However, whether it obviates the need to rely on a comparator depends on which value underlies prohibitions on discrimination. We consider three competing accounts and show how each account has distinctive implications for our central question - namely, whether moving to a test of unfavourable treatment eliminates the need to consider a comparator. For reasons that will be explained in Part IV, we do not seek to resolve the dispute between these competing accounts, and so do not offer a concluded view as to whether adopting a test of unfavourable treatment obviates the need to rely on a 
comparator. However, we do provide a conceptual map of the issues that need to be resolved before a concluded view can be reached.

\section{Part I - The test of unfavourable treatment}

As mentioned in the Introduction, there is a widely held view that, in order to overcome the problems with the use of a comparator, it is desirable to move to a test of unfavourable treatment for the purposes of the harm element of a claim in direct discrimination. This view is reflected in recent proposed and actual legislative changes. Hence, for instance, the draft Human Rights and Anti-Discrimination Bill 2012 (Cth) employs a test of unfavourable treatment in its provisions dealing with direct discrimination. ${ }^{5}$ As the Explanatory Notes to the Bill make clear, the motivation for this is to remove the need to rely on a comparator and hence to avoid the problems to which reliance on a comparator gives rise. ${ }^{6}$ While it is unlikely that legislation based on the draft Bill will be introduced into Parliament, at least in the short term, ${ }^{7}$ the draft Bill does provide a clear illustration of the view that adopting a test of unfavourable treatment is desirable because it will obviate the need to rely on a comparator.

There have also been moves in other jurisdictions to replace a test of less favourable treatment with one of unfavourable treatment, with the expectation that this will eliminate the need to rely on a comparator. ${ }^{8}$ For example, recently, the Victorian Parliament enacted the Equal Opportunity Act 2010 (Vic), which defines direct discrimination in terms of treating a person unfavourably because of a protected attribute. ${ }^{9}$ As the Explanatory Memorandum states, this was done to 'overcome the unnecessary technicalities associated with identifying an appropriate comparator when assessing direct discrimination'. ${ }^{10}$ Similarly, the United Kingdom's Equality Act 2010 employs a test of unfavourable treatment in respect of claims of direct discrimination relating to pregnancy, and some claims relating to disability, though

\footnotetext{
${ }^{5}$ Pursuant to $\mathrm{cl} \mathrm{19(1)} \mathrm{of} \mathrm{the} \mathrm{Bill,} \mathrm{a} \mathrm{person} \mathrm{discriminates} \mathrm{against} \mathrm{another} \mathrm{person} \mathrm{'if} \mathrm{the} \mathrm{first} \mathrm{person} \mathrm{treats,} \mathrm{or}$ proposes to treat, the other person unfavourably' (emphasis added).

${ }^{6}$ See the Explanatory Notes, Human Rights and Anti-Discrimination Bill 2012 (Cth) 28. See also the Discrimination Law Experts' Group, Submission to Attorney-General's Department, Consolidation of Commonwealth Anti-Discrimination Laws Project, 13 December 2011. The Group recommended the use of a test of unfavourable treatment (at 8), in order to remove the need to rely on a comparator (at 11).

${ }^{7}$ See Human Rights Law Centre, Delay on Stronger Anti-Discrimination Laws Met with Extreme Disappointment (20 March 2013) <http://www.hrlc.org.au/delay-on-stronger-anti-discrimination-laws-metwith-extreme-disappointment>; Law Council of Australia, Anti-Discrimination Laws $<$ http://www.lawcouncil.asn.au/lawcouncil/index.php/current-issues/anti-discrimination>.

${ }^{8}$ Interestingly, the ACT has had such a test since 1991: Discrimination Act 1991 (ACT), s 8(1)(a).

${ }^{9}$ Section 8 of the Act states that '[d]irect discrimination occurs if a person treats, or proposes to treat, a person with an attribute unfavourably because of that attribute' (emphasis added).

${ }^{10}$ See Explanatory Memorandum, Equal Opportunity Bill 2010 (Vic) 12-13.
} 
it retains a test of less favourable treatment with regard to claims on other grounds. ${ }^{11}$ Where a test of unfavourable treatment is employed in the Equality Act, the motivation for its use is to obviate the need to rely on a comparator to determine whether the harm element is made out. $^{12}$

It might be argued that the above suggests that the purpose behind these (proposed and actual) legislative changes is to eliminate the need to rely on a comparator and that this, in turn, strongly supports the conclusion that these changes $d o$ eliminate the need to rely on a comparator. It is, after all, a cardinal rule of statutory interpretation that statutes should, where possible, be read in a way which promotes their purpose. ${ }^{13}$ Here, this seems to require reading the provisions mentioned in the preceding two paragraphs in such a way that recourse to a comparator is not needed.

The position, however, is not so straightforward. As famously stated by the US Supreme Court, '[N]o legislation pursues its purposes at all costs. ${ }^{14}$ One reason for this is that legislation invariably involves balancing different concerns, and giving full effect to one concern may come at the expense of another. As we shall see in Part II, this consideration weighs heavily against one influential way of interpreting the provisions referred to above so as to eliminate the need to rely on a comparator.

Partly for this reason, courts attach a great deal of weight to the wording and structure of a statute when ascertaining its purpose. ${ }^{15}$ In the case of the provisions with which we are concerned, it is therefore important to note that Parliament chose to achieve its goal of eliminating the need to have recourse to the comparator by introducing a test of unfavourable

\footnotetext{
${ }^{11}$ Equality Act 2010 (UK) ss 13, 15, 17-18.

12 See the explanation provided in Bob Hepple, Equality: The New Legal Framework (Hart Publishing, 2011) 53-4, 73-4. As to why it was thought to be particularly important to remove the need to rely on a comparator in these contexts, see ibid, and Fredman, above n 2, 169-74.

13 Acts Interpretation Act 1901 (Cth), s 15AA; Interpretation Act 1987 (NSW), s 33; Acts Interpretation Act 1954 (Qld), s 14A; Acts Interpretation Act 1915 (SA), s 22; Acts Interpretation Act 1931 (Tas), s 8A; Interpretation of Legislation Act 1984 (Vic), s 35(a); Interpretation Act 1984 (WA), s 18.

${ }^{14}$ Rodriguez v United States, 480 US 522, 525-6 (1987), cited with approval in Construction Forestry Mining \& Energy Union v Mammoet Australia Pty Ltd (2013) 248 CLR 619, [40]. See also Carr v WA (2007) 232 CLR 138, [5]-[7] (Gleeson CJ).

${ }^{15}$ Lacey v Attorney-General (Qld) (2011) 242 CLR 573, 592 (French CJ, Gummow, Hayne, Crennan, Kiefel and Bell JJ); Certain Lloyd's Underwriters v Cross (2012) 248 CLR 378, [25]-[26] (French CJ and Hayne J).
} 
treatment. Each of those provisions states that, in order for a claim in direct discrimination to succeed, the alleged discriminator must have treated the complainant unfavourably. ${ }^{16}$

This suggests that it is too facile to claim that the purpose underlying the introduction of the test of unfavourable treatment in the case of the Human Rights and Anti-Discrimination Bill 2012 (Cth), the Equal Opportunity Act 2010 (Vic) and the Equality Act 2010 (UK) is to obviate the need to use a comparator. ${ }^{17}$ Rather, the purpose is to obviate the need for a comparator by introducing a test of unfavourable treatment - that is, to achieve a particular end (eliminating the need for a comparator) by a particular means (introducing a test of unfavourable treatment). ${ }^{18}$

This more nuanced characterisation of the purpose of these provisions suggests that we cannot assume, a priori, that they do, in fact, obviate the need to have recourse to a comparator. Rather, any argument that they have this effect has to show how this result follows from the utilisation of a test of unfavourable treatment. In other words, it needs to be shown that the words 'treats ... the other person unfavourably' in the Commonwealth Bill, and the corresponding phrases contained in the Victorian and United Kingdom Acts, can bear a meaning that eliminates the need to rely on a comparator. We investigate whether this can be shown in Parts II - IV below.

At least one court has been similarly cautious about whether these legislative changes have the desired effect of eliminating the need to rely on a comparator. There are some administrative decisions that treat a test of unfavourable treatment as dispensing with the need for a comparator, most notably Re Prezzi and Discrimination Commissioner and Quest Group Pty Ltd, ${ }^{19}$ which we will look at in detail in Part II. However, despite noting the decision in Prezzi, the Victorian Court of Appeal, in Aitken v State of Victoria (Department of

\footnotetext{
${ }^{16}$ Human Rights and Anti-Discrimination Bill 2012 (Cth), cl 19(1) ('treats ... the other person unfavourably'); Equal Opportunity Act 2010 (Vic), s 8 ('treats ... a person ... unfavourably'); Equality Act 2010 (UK), ss 15(1)(a) ('A treats B unfavourably'), 17(2)\&(3) ('A treats her unfavourably'), 18(2)-(4) ('A treats her unfavourably').

${ }^{17}$ This is true despite the statements in the explanatory notes and memoranda referred to above. Any use of those statements to ascertain the purpose of the Australian provisions must take account of the High Court jurisprudence concerning how statutory purpose is to be ascertained (and concerning the limits on the proper use of extrinsic materials). See above n 15, and also Alcan (NT) Alumina Pty Ltd v Commissioner of Territory Revenue (2009) 239 CLR 27, [47] (Hayne, Heydon, Crennan and Kiefel JJ).

${ }^{18}$ Our thinking on this issue has benefitted from reading Richard Ekins, The Nature of Legislative Intent (Oxford University Press, 2012).

19 (1996) 39 ALD 729, 735-7 ('Prezzi'). See also Re ACT Health and Community Care Service and Discrimination Commissioner (1998) 53 ALD 779; Jv Federal Capital Press of Australia Ltd [1999] ACTDT 2; Johnston v Dallarooma Pty Ltd [1999] ACTDT 8; Edgley v Federal Capital Press of Australia Pty Ltd [2001] FCA 379; Ezzat v ACT Corrective Services [2001] ACTDT 2; Firestone v Australian National University [2009] ACTDT 1; Bell v DeCastella [2013] ACAT 27.
} 
Early Childhood Development), ${ }^{20}$ expressly left the issue open with regard to the Equal

Opportunity Act 2010 (Vic). The Court stated that 'the question whether a comparator group is required under the 2010 Act remains an unresolved question of law[.], 21

\section{Part II - Detriment and Setback to Interests}

Let us turn now to the question of how the test of unfavourable treatment is to be understood. There is no general definition of this term in any of the statutory provisions with which we are concerned. ${ }^{22}$ That said, the Explanatory Notes to the Human Rights and AntiDiscrimination Bill 2012 (Cth) indicate that unfavourable treatment is to be understood as meaning 'treatment [that] is detrimental to the person'. ${ }^{23}$ However, it is not clear that tests of unfavourable treatment in the other legislative provisions mentioned in Part I should be understood in this way. More importantly, what is meant by 'detrimental' in this context is not explained. The danger, therefore, is that one unanalysed term ('unfavourable treatment') will be replaced with another ('treatment that is detrimental').

However, one might seek to give content to the notion of detrimental treatment by looking to see how the notion of detriment has been understood in a closely related context. The law of direct discrimination distinguishes between the question of whether A discriminates against $\mathrm{B}$ (which is ascertained by reference to the harm and causation elements, distinguished in the Introduction above) and the further question of whether the discrimination occurs in a context that renders it unlawful (eg employment, education or the provision of services). ${ }^{24}$ Of these contexts (which we will henceforth refer to as the 'spheres of activity') some make use of the concept of detriment. For example, s 18(2)(d) of the Age Discrimination Act 2004 (Cth) states:

It is unlawful for an employer or a person acting or purporting to act on behalf of an employer to discriminate against an employee on the ground of the employee's age:

\footnotetext{
20 [2013] VSCA 28.

${ }^{21}$ Ibid [46]. However, cf Slattery v Manningham City Council [2013] VCAT 1869, [45]-[53], where the tribunal held that the test of unfavourable treatment in the Equal Opportunity Act 2010 (Vic) does not require consideration of a comparator. See also Kuyken v Lay [2013] VCAT 1972.

22 There is a partial definition in cl 19(2) of the Human Rights and Anti-Discrimination Bill 2012 (Cth):

To avoid doubt, unfavourable treatment of the other person includes (but is not limited to) the following:

(a) harassing the other person;

(b) other conduct that offends, insults or intimidates the other person.

However, as we shall see shortly, the Explanatory Notes suggest that unfavourable treatment is to be understood as treatment that is detrimental. The Notes add that $\mathrm{cl} \mathrm{19(2)} \mathrm{is} \mathrm{intended} \mathrm{to} \mathrm{make} \mathrm{it} \mathrm{clear} \mathrm{that} \mathrm{harassment} \mathrm{and}$ offensive, insulting and intimidating conduct amount to detrimental conduct. See Explanatory Notes, Human Rights and Anti-Discrimination Bill 2012 (Cth) 26.

${ }^{23}$ Explanatory Notes, Human Rights and Anti-Discrimination Bill 2012 (Cth) 26. See also Discrimination Law Experts' Group, above n 6, 11.

${ }^{24}$ For example, s 5(1) of the Disability Discrimination Act 1995 (Cth) sets out what it is for A to (directly) discriminate against $\mathrm{B}$, while Part 2 of the Act sets out the contexts in which discrimination is unlawful.
} 
(d) by subjecting the employee to any other detriment.

There are two different approaches taken in the case law to the meaning of 'detriment' for the purpose of the spheres of activity. On the first approach, 'detriment' is taken to mean 'loss, damage or injury'. ${ }^{25}$ On the second approach, 'detriment' is understood in terms of placing someone under a disadvantage. ${ }^{26}$

This second approach fits with the limited case law that exists on the meaning of 'unfavourable' under state and territory legislation which employs a test of unfavourable treatment. That case law generally understands unfavourable treatment in terms of treatment that is adverse to the complainant, or places her under a disadvantage. ${ }^{27}$

However, it is not clear that the notion of treatment that is adverse to the complainant, or places her under a disadvantage, provides any more guidance in this context than does the notion of treatment that is unfavourable to the complainant. As we will see, some of the cases that have used the former notion seek to make it more precise and transparent by understanding it in terms of a setback to interests. However, simply understanding unfavourable treatment in terms of treatment that is adverse or disadvantageous to the complainant, without further specification of what this means, does not advance the analysis very far. Once again, this would merely be to replace one unanalysed term ('unfavourable' or 'detrimental') with a synonym that is similarly unanalysed ('adverse' or 'disadvantageous').

That said, some cases have attempted to elaborate upon the notion of treatment that is adverse or disadvantageous. Most notable in this regard is Re Prezzi and Discrimination Commissioner and Quest Group Pty Ltd, ${ }^{28}$ a decision of the ACT Administrative Appeals Tribunal. Prezzi concerned s 8(1)(a) of the Discrimination Act 1991 (ACT), which states that 'a person discriminates against another person if ... the person treats or proposes to treat the other person unfavourably because the other person has [a protected] attribute'. The tribunal held that s $8(1)(a)$

\footnotetext{
${ }^{25}$ See, eg, Bonella v Wollongong City Council [2001] NSWADT 194; Vassallo v Jetswan Pty Ltd [2010] FMCA 708; Mulcahy v Minchinton [2012] FMCA 380.

${ }^{26}$ See, eg, O'Callaghan v Loder [1983] 3 NSWLR 89; Leonard v Youth Hostels Association of Victoria (1995) EOC 92-763; Varas v Fairfield City Council [2009] FCA 689.

${ }^{27}$ See, eg, Re Prezzi and Discrimination Commissioner and Quest Group Pty Ltd (1996) 39 ALD 729; Edgley v Federal Capital Press of Australia Pty Ltd [2001] FCA 379; Ezzat v ACT Corrective Services [2001] ACTDT 2; Bell v DeCastella [2013] ACAT 27; Slattery v Manningham City Council [2013] VCAT 1869.

28 (1996) 39 ALD 729.
} 
does not invite a comparison between the way in which a person who has a particular attribute is treated compared with a person without that attribute or who has a different attribute. All that is required is an examination of the treatment accorded the aggrieved person or the conditions upon which the aggrieved person is or is proposed to be dealt with. ${ }^{29}$

More precisely, what must be ascertained for the purpose of assessing whether there has been unfavourable treatment 'is whether the consequences of the dealing with the complainant are favourable to the complainant's interests or are adverse to the complainant's interests'. ${ }^{30}$

We will call this approach to understanding the test of unfavourable treatment the 'setback to interests approach'. For our purposes, the most significant feature of the setback to interests approach, as articulated in Prezzi, is that it purports not to require reliance on a comparator when ascertaining whether there is unfavourable treatment. Instead, whether the treatment in question is unfavourable turns on whether it is adverse to the complainant's interests.

The claim that the setback to interests approach avoids the need to have regard to a comparator presupposes that the relevant interests are not themselves comparative, or at least that the complainant can always point to an interest which is not comparative (even if there are other interests at stake which are comparative). ${ }^{31}$ The latter, at least, is plausible. Consider, for example, a person, Amrita, whose employment has been terminated. Among Amrita's interests that have been adversely affected are her financial interests - having lost her job, she is in a worse financial position than she was previously. Moreover, Amrita can show that her interests have been adversely affected without needing to rely on a comparator - she is now in a worse financial position than she was previously, regardless of how anyone else has been treated or would have been treated. ${ }^{32}$

Similarly, the termination of Amrita's employment may well have an adverse impact on her self-esteem. Just as she has an interest in maintaining her financial position, she also has an

\footnotetext{
${ }^{29}$ Ibid 736.

${ }^{30}$ Ibid. Cases that have followed Prezzi on this point include: $J v$ Federal Capital Press of Australia Ltd [1999] ACTDT 2; Johnston v Dallarooma Pty Ltd [1999] ACTDT 8; Firestone v Australian National University [2009] ACTDT 1; Kuyken v Lay [2013] VCAT 1972.

${ }^{31}$ For our purposes, an interest counts as comparative if, in order to ascertain whether the interest has been adversely affected, one needs to consider the position of people other than the person whose interest it is. ${ }^{32}$ This is not to deny that Amrita could present the setback to her financial interests in a way that does make use of a comparator. For example, the fact that she has lost her job is likely to mean that she is in a financially disadvantaged position relative to her former co-workers (assuming that they retained their jobs). However, the point is that Amrita does not need to make use of a comparator in this way in order to show that there has been a setback to her interests.
} 
interest in maintaining a certain level of self-esteem. ${ }^{33}$ Again, this may provide a way for Amrita to establish that her interests have been adversely affected without needing to rely on a comparator. Amrita's self-esteem may well have suffered as a result of the termination of her employment, regardless of how anyone else has been treated. ${ }^{34}$

There is a further reason to think that reliance on a comparator will not be necessary under the setback to interests approach. Recall that, in order for a claim in direct discrimination to be successful, there must not only be unfavourable treatment, but - in addition - that treatment must occur within one of the specified spheres of activity (for example, employment, education, the provision of goods, services and facilities, or the provision of accommodation). ${ }^{35}$ Whatever the position with respect to other areas of endeavour, there will almost inevitably be non-comparative interests at stake in each of the specified spheres of activity (though there may be comparative interests at stake in those spheres as well). For example, we have an interest in being educated and employed, irrespective of the position of other people.

However, while the complainant need not rely on a comparator to establish a setback to her interests, there may be some cases where she has an incentive to do so. Consider, for example, a case where a female employee is refused a promotion that has been awarded to male employees whose performance has been (and promises to be) no better than hers. If she wants to bring a claim of direct discrimination, it is open to her (under the setback to interests approach) to point to a non-comparative interest that has been adversely affected. For example, a promotion typically entails a pay-rise and, no matter how much a person is paid, it is most likely in their financial interests to be paid more. However, reliance on a non-

\footnotetext{
${ }^{33}$ As Matthew Conaglen pointed out to us, it might be contended that the setback to interests approach is concerned only with legally recognised interests and that the interest in maintaining a certain level of selfesteem is not legally recognised. We consider below whether the setback to interests approach is concerned only with legally recognised interests. In any case, there is some reason to think that the interest in maintaining a certain level of self-esteem is legally recognised. While it is unclear how one is to ascertain which interests are legally recognised, one possibility is that one should look to the matters in respect of which remedies are granted. In discrimination law, remedies are granted not only for financial loss, but also for hurt to feelings that occurs as a result of the discriminatory treatment: Alexander v Home Office [1988] 2 All ER 118, 122 (cited with approval in Hall v Sheiban (1989) 20 FCR 217, 256); Gilroy v Angelov (2000) 181 ALR 57, 76; Johanson v Blackledge (2001) 163 FLR 58, 84; Wattle v Kirkland (No 2) [2002] FMCA 135, [71]. We submit that compensating for hurt to feelings in this context is intimately connected to protecting complainants' self-esteem, suggesting that the interest in maintaining a certain level of self-esteem may be a legally recognised interest: see Power $v$ Aboriginal Hostels [2004] FMCA 452, [72]-[76].

${ }^{34}$ Again, it may be that Amrita could, if she chose, rely on a comparator to establish that there has been a setback to her interest in maintaining a certain level of self-esteem. The point in the text is simply that Amrita need not rely on a comparator to establish a setback to this interest.

${ }^{35}$ See, eg, Human Rights and Anti-Discrimination Bill 2012 (Cth), s 22; Equal Opportunity Act 2010 (Vic), Part 4.
} 
comparative interest may not go to the heart of the female employee's concern. It may be that the essence of her complaint is not that she has not been promoted per se, but that she has not been promoted in circumstances where her male co-workers have. To bring this complaint within the setback to interests approach, she will need to appeal to a comparative interest, such as her interest in being treated justly (in these circumstances, by being given the same promotion as her male co-workers). ${ }^{36}$

Nevertheless, the fact that a complainant may sometimes want to present their case by appealing to a comparative interest that has been adversely affected does not necessarily mean that the setback to interests approach fails to achieve the aim behind adopting the test of unfavourable treatment. Under the setback to interests approach as described above, there is no requirement that the complainant make use of the comparator. She is, however, free to do so if she wishes. ${ }^{37}$

There remains, however, a significant problem with the setback to interests approach. Consider the range of interests we have already discussed: financial interests, an interest in maintaining a certain level of self-esteem, an interest in being employed and in being educated, and an interest in being treated justly. As this suggests, there is a vast range of interests to which appeal could be made to establish unfavourable treatment under the setback to interests approach. ${ }^{38}$

This suggests that it will be very easy for a complainant to establish unfavourable treatment on the setback to interests approach. (Just how easy it is will be demonstrated shortly.) It might be thought that this is an attractive consequence of that approach, especially given the motivation behind adopting a test of unfavourable treatment in the first place. However, in a significant range of instances, this leads to highly counter-intuitive consequences, suggesting

\footnotetext{
${ }^{36}$ We elaborate on the notion of justice in play here in Part IV below, when we discuss John Gardner's view about the value underlying prohibitions on discrimination.

${ }^{37}$ There may, however, be rare cases in which the only interests at stake are comparative, and hence in which reliance on a comparator is unavoidable. If so, this may represent a further problem with the setback to interests approach, in addition to the far more serious problem we discuss below.

${ }^{38}$ It is true that the treatment accorded to the complainant may not always be to his or her ultimate detriment. For example, while a failure to employ a particular applicant will adversely affect his or her interests in some ways (financially and perhaps in terms of self-esteem), it may advance his or her interests in other ways. It may, for example, mean that he or she has more time to spend with his or her family, and this may, in some cases, outweigh the setback to his or her interests. However, the setback to interests approach is not concerned with this sort of overall balancing of interests. Clearly, where an employee is refused a promotion because of his or her race (for example), it would not be open to the alleged discriminator to argue that there has been no setback to the employee's interests because the employee is able to spend more time with his or her family.
} 
that the setback to interests approach is over-inclusive. ${ }^{39}$ For example, imagine that there is a government scheme for providing support for people with a disability. Imagine, further, that Phuong who, as a result of an accident, has suffered injuries which render him disabled, requests funding pursuant to this scheme so that he can go on a 6 week cruise to London. ${ }^{40}$ On the setback to interests approach, refusal of this request is likely to constitute unfavourable treatment, because going on the cruise is likely to promote his interests (for example, it might well promote his interest in being well-travelled, and in obtaining exposure to new experiences and possibly other cultures). Yet this conclusion seems unsatisfactory. It seems implausible to claim that we treat Phuong unfavourably by not providing him with a six week cruise to London so that he can experience the joys of travel.

It might be objected that the setback to interests approach is concerned only with legally recognised interests, and a person's interest in being well-travelled is not a legally recognised interest. If so, there may not be a setback to interests (in the relevant sense) in denying Phuong the cruise. However, it is not clear that this objection is sound. Obviously, there is a sense in which the setback to interests approach - being a (putative) legal test - is concerned with legally recognised interests. By definition, if a particular interest is not relevant under the setback to interests approach, then it is not legally recognised, at least in this context. The real question is what counts as a legally recognised interest for present purposes. Is it all interests that a person may have (as identified, perhaps, via moral philosophy) or is it only interests that are recognised elsewhere in the law, either elsewhere in discrimination law or elsewhere in any area of law?

There is no explicit statement in Prezzi that the interests relevant to the setback to interests approach are confined to those interests recognised elsewhere in the law. Perhaps this was regarded by the tribunal as going without saying. That would be surprising, however, given the obvious need to provide an account of what interests are legally recognised elsewhere in

\footnotetext{
${ }^{39}$ The extent of the over-inclusiveness will depend on whether one adopts an objective or subjective account of interests. On the latter, a person's interests are fixed by reference to the things he or she desires; on the former, it is possible for something that a person desires not to be in his or her interests (and vice versa). In the text, we presuppose an objective account, but it is worth noting that the problem of over-inclusiveness is even more pressing on a subjective account. On a subjective account, all that would be needed for there to be unfavourable treatment is for the complainant to be treated in a way he or she desires not to be treated. This problem was noted by Senior Member Anforth when he said 'a person with a disability could consider themselves treated "unfavourably" for no other reason than they did not obtain what they wanted': $D$ and Commissioner for Social Housing (Discrimination) [2010] ACAT 62, [99]. As we shall see, it is largely for this reason that Senior Member Anforth rejected the setback to interests approach in favour of the reasonable expectations approach discussed in Part III.

${ }^{40}$ This is a modified version of an example given by Senior Member Anforth in $D$ : ibid.
} 
the law, if only those interests are to be protected. Is it interests that are recognised by discrimination law in particular, or by any area of law? And, in either case, how do we tell what interests the law recognises? There are not often explicit statements in cases or legislation of what interests an area of law does or does not protect. Even where there are such statements, they are rarely sufficiently detailed so as to provide the sort of guidance that would be necessary if the setback to interests approach were to be limited to interests recognised elsewhere in the law.

More importantly, even if the setback to interests approach were understood as being concerned only with interests recognised elsewhere in the law, this would only reduce the extent to which that approach is over-inclusive; it would not eliminate the problem. To see this, consider another example, involving Susan, who asks her employer for a million dollar raise, which the employer refuses. This is in itself a setback to Susan's financial interests, and it seems plausible to regard financial interests as legally recognised in the relevant sense. ${ }^{41}$ Therefore, on the setback to interests approach, Susan has been treated unfavourably. ${ }^{42}$ Yet it seems perverse to say that the mere fact that someone has been denied a million dollar raise is sufficient, by itself, to satisfy the harm element in an action for direct discrimination.

Of course, there could be further facts that suggest that Susan was treated unfavourably. If her male colleagues did receive a million dollar raise, but Susan did not, then we might well think that she has been treated unfavourably. But the crucial point is that, on the setback to interests approach, such further facts are not needed to establish that she has been treated unfavourably - the mere fact that she has been refused the raise is enough. It is this consequence of the setback to interests approach that is counter-intuitive.

Nonetheless, a supporter of the setback to interests approach may not be perturbed by the over-inclusiveness of that approach. While the setback to interests approach renders the test of unfavourable treatment over-inclusive, it does not necessarily render the overall test for

\footnotetext{
${ }^{41}$ As already mentioned, it is not clear how we are to ascertain which interests are recognised elsewhere in the law. However, financial interests would appear to be an especially likely candidate. After all, compensation is often awarded as a remedy in discrimination law, and in many other areas of law, for financial losses the complainant has sustained.

${ }^{42}$ Someone might seek to avoid this conclusion by distinguishing between a setback to interests, on the one hand, and, on the other, a failure to advance interests. It could then be argued that, in the example we have provided, the refusal to grant Susan a raise is a failure to advance her interests, not a setback to her interests. However, it is not clear how this distinction can be drawn in a way that avoids obvious objections. For example, a failure to promote an employee (by reason of a protected attribute) is a paradigmatic example of direct discrimination in an employment context, and so would have to count as a setback to interests. But, if a failure to promote counts as a setback to interests, it is very difficult to see how a failure to provide a raise could, on any sort of principled basis, be treated differently.
} 
direct discrimination over-inclusive. Establishing unfavourable treatment is not sufficient to establish a claim in direct discrimination. One must also establish that the unfavourable treatment was accorded 'on the ground of' the complainant's protected attribute. It might be argued that, in cases where the setback to interests approach is over-inclusive, this further requirement (which we earlier called the 'causation element') will not be made out, and so the overall test for direct discrimination will not be over-inclusive. Consider, again, the example of Susan. If she was denied the million dollar raise for reasons that had nothing to do with any protected attribute, then (even though she has been treated unfavourably according to the setback to interests approach) the causation element of a claim in direct discrimination would not be made out, and so Susan's claim would fail.

However, even if it is true that the over-inclusiveness of the setback to interests approach can be cured by appeal to the causation element, this still fails to give full effect to the purpose underlying the legislative changes. As we saw in Part I, that purpose is not just to eliminate the need to have recourse to a comparator, but to do so via the implementation of a test of unfavourable treatment. Where Parliament adopts a test of unfavourable treatment, the very fact that it does so indicates that Parliament intends that this test plays a role, in the sense that some claims in direct discrimination could fail by virtue of the complainant being unable to show that they were treated unfavourably. But, if Parliament intends that some claims could fail on the basis that there was no unfavourable treatment, Phuong's and Susan's claims would surely be among them. Yet, as we have seen, pursuant to the setback to interests approach, there is unfavourable treatment in Susan's case, and (depending on whether the approach is limited to legally recognised interests) possibly Phuong's case as well. This strongly suggests that the setback to interests approach does not, in fact, give effect to the purpose underlying the relevant legislative changes. Accordingly, the setback to interests approach is unsatisfactory.

\section{Part III - Reasonable Expectations}

Let us turn now to consider an alternative way of understanding the test of unfavourable treatment. According to this alternative understanding, the alleged discriminator treats the complainant unfavourably if a reasonable expectation on the part of the complainant is disappointed as a result of the treatment. 
This 'reasonable expectations' approach is suggested by Senior Member Anforth in $D$ and Commissioner for Social Housing (Discrimination). ${ }^{43}$ In this case, the Tribunal member recognises something akin to the over-inclusiveness problem identified in Part II. ${ }^{44}$ His suggestion is that this problem can be overcome if we assess whether or not treatment is unfavourable by reference to the complainant's 'realistic or reasonable expectations, objectively determined.' ${ }^{45}$ Despite the reference to the complainant's reasonable expectations, we take the suggestion to be that we should look to the expectations that a reasonable person with the protected attribute in question would have in the circumstances. ${ }^{46}$

Importantly, the reasonable expectations approach avoids the over-inclusiveness of the setback to interests approach. The over-inclusiveness problem for the setback to interests approach arises where the complainant has no entitlement that her interests not be adversely affected in the way complained of. By contrast, on the reasonable expectations approach, there would be unfavourable treatment only where the treatment in question would disappoint an expectation that would be possessed by a reasonable person who has the protected attribute in question. Hence, for example, Phuong would not have been treated unfavourably as a result of being denied the six week cruise to London, since any expectation he had of receiving the cruise would not have been held by a reasonable person in his position. Similarly, unless further unusual facts were present, a reasonable person in Susan's position would not have expected to have been awarded a $\$ 1,000,000$ raise, and so Susan would not be treated unfavourably by virtue of being denied such a raise.

It might also be thought that understanding unfavourable treatment in terms of a disappointment of reasonable expectations avoids the need to consider a comparator. On its face, this understanding seems to make the question of whether the complainant has been treated unfavourably turn on what expectations a reasonable person with the protected

\footnotetext{
43 [2010] ACAT 62.

${ }^{44}$ Senior Member Anforth observed that 'If the logic in Prezzi is correct ... a person with a disability could consider themselves treated "unfavourably" for no other reason than they did not obtain what they wanted': ibid [99]. This observation does, however, presuppose (in its reference to 'what they wanted') a subjective account of interests: cf above $\mathrm{n} 39$.

${ }^{45}$ Ibid [101].

${ }^{46}$ We are grateful to an anonymous referee for suggesting this interpretation. Among its other virtues, it fits with the way that tests of reasonableness are understood in other areas of the law (e.g. tests of reasonable foreseeability in the tort of negligence).
} 
attribute would have had, not on how other people who lack the protected attribute have been, or would have been, treated. ${ }^{47}$

However, the position is not so clear-cut. Consideration of the way in which other people, in positions similar to that of the complainant but lacking the complainant's protected attribute, have been treated may be essential to the application of the reasonable expectations approach. It may be that, in many cases, what gives rise to the expectation on the part of a reasonable person with the protected attribute is the very fact that other people, in similar positions to that of the complainant but without the protected attribute, have received treatment of the kind in question. For example, the fact that other people, who do not possess a protected attribute and who have performed their work to a certain level, are promoted may give rise to an expectation on the part of a reasonable person, who does have a protected attribute and who has also performed at that level, that he or she will also be promoted. In cases of this kind, the complainant will need to rely on a comparator as an essential part of establishing that there was a reasonable expectation to certain treatment.

It might be objected that what gives rise to the reasonable expectation in the example in the previous paragraph is simply that the complainant has met the criteria for promotion, not that other people have been promoted when they met those criteria. However, often the criteria for promotion will be vague, and it will be uncertain how different criteria are to be weighed against each other. In such cases, how the vagueness and uncertainty have been resolved in the past will be crucial to assessing what now counts as a reasonable expectation.

Alternatively, it might be argued that the aim of adopting a test of unfavourable treatment is to go beyond the understanding of reasonable expectations suggested in the previous two paragraphs, according to which what counts as a reasonable expectation will often depend on how other, similarly placed, people have been treated. After all, in the case of the proposed and actual legislative changes discussed in Part I, the stated aim of adopting a test of unfavourable treatment is to eliminate the need to consider a comparator. ${ }^{48}$ It is not immediately clear, however, what alternative understanding of reasonable expectations could

\footnotetext{
${ }^{47}$ As Senior Member Anforth notes, the reasonable expectations approach is, in a sense, comparative, since it involves comparing the treatment that the complainant actually received with the treatment that he or she could reasonably have expected to have received: D and Commissioner for Social Housing (Discrimination) [2010] ACAT 62, [101]. However, this appears to be a different sort of comparison from the one with which we are concerned - namely, a comparison between how the complainant was treated and how a person without the complainant's protected attribute was, or would have been, treated.

${ }^{48}$ Though recall our earlier point that the legislative purpose is not simply to eliminate the need to consider a comparator, but to do this by introducing a test of unfavourable treatment.
} 
be offered in place of that suggested in the previous two paragraphs. One possibility is that what expectations count as reasonable in this context should be sensitive to the aim of adopting a test of unfavourable treatment. However, to the extent that the aim is to avoid the need to consider a comparator, it does not suggest a positive understanding of what expectations count as reasonable - all it tells us is that we need an understanding that does not require recourse to a comparator.

More promisingly, one could appeal to the value underlying prohibitions on discrimination to answer the question of what expectations count as reasonable in the context of a claim of direct discrimination. It seems plausible to suggest that what expectations count as reasonable for the purposes of a claim in direct discrimination should be sensitive to the value that this area of law is ultimately concerned to protect and promote. Indeed, if what counts as a reasonable expectation is sensitive to the value underlying prohibitions on discrimination, we can eliminate references to reasonable expectations and understand unfavourable treatment directly in terms of that underlying value. So if, for example, the value underlying prohibitions on discrimination is equality, unfavourable treatment can be understood as unequal treatment. In the next Part, we will first suggest some reasons in favour of understanding unfavourable treatment in terms of the value underlying prohibitions on discrimination, whatever it may be. We will then consider several accounts of what that value might be, and whether they support an understanding of unfavourable treatment that eliminates the need to consider a comparator.

\section{Part IV - The Value-Based Approach}

In Parts II and III, we considered two possible understandings of unfavourable treatment. We saw that, while the setback to interests approach eliminates the need to use a comparator, it is over-inclusive and, for that reason, unsatisfactory. By contrast, the reasonable expectations approach avoids the over-inclusiveness of the setback to interests approach, but may not succeed in eliminating the need to use a comparator. In the present Part, we will consider an alternative approach to understanding the test of unfavourable treatment. Pursuant to this approach, the test of unfavourable treatment is to be understood in light of the value underlying prohibitions on discrimination.

There are at least two advantages to adopting such an approach. Firstly, there is good reason to think that, like the reasonable expectations approach, the present approach avoids the over- 
inclusiveness of the setback to interests approach. If we assess what counts as unfavourable treatment by reference to the value underlying prohibitions on discrimination, then the test of unfavourable treatment will be satisfied only in circumstances where that value is infringed by the treatment accorded to the complainant. In other words, the test of unfavourable treatment will be satisfied only in circumstances where there is good reason to find that the test is satisfied (the reason in question being derived from the need to promote the value underlying prohibitions on discrimination), with the result that the test will not be overinclusive. $^{49}$

Secondly, treating the test of unfavourable treatment as being responsive to the value underlying prohibitions on discrimination fits nicely with the way in which we assess whether there has been unfavourable treatment in other contexts. For instance, if, after a fair trial, a person is imprisoned for a serious offence that they in fact committed, we would not be inclined to say that they have been treated unfavourably. ${ }^{50}$ This is so despite the fact that being sent to jail clearly amounts to a setback to the offender's interests. ${ }^{51}$ Furthermore, while it is true that the offender would not, in those circumstances, have a reasonable expectation not to be imprisoned, it does not seem to be this fact that explains why we are inclined not to regard them as having been treated unfavourably. Rather, it is the fact that imprisoning the offender gives effect to the values underlying the practice of criminal punishment - perhaps certain retributivist values - that best explains why we do not regard the treatment as having been unfavourable. (The best way of seeing this is to consider a case where the convicted person is, in fact, innocent. In such a case, we would be inclined to say that they have been treated unfavourably, and the fact that they are innocent - and hence not an appropriate subject of retribution - is sufficient in itself to show this. We would not need to also consider whether a reasonable expectation on the part of the convicted person has been disappointed.)

\footnotetext{
${ }^{49}$ It might be thought that, while this approach avoids the over-inclusiveness problem, it is empty of content (since it effectively says that the test of unfavourable treatment is made out where there is good reason for it to be made out). However, the content comes from the particular account of the value that underlies prohibitions on discrimination. We consider three rival accounts of that value below.

${ }^{50} \mathrm{We}$ assume, for the sake of the example, that the length of the sentence is proportionate to the seriousness of the offending, and that the offence itself is not objectionable (cf, for example, laws which criminalise homosexuality).

${ }^{51}$ Recall that a person may suffer a setback to their interests even if they benefit in some ways from the treatment in question: see above $\mathrm{n} 38$. Thus, even if one believes that a person may benefit from being sent to jail (because they will have the opportunity to be rehabilitated), being sent to jail clearly involves a setback to their interests (eg because it involves a deprivation of their liberty).
} 
This is, of course, a different context from that of direct discrimination. Nevertheless, the fact that this is a natural way of understanding the concept of unfavourable treatment in the context of punishment lends support to the suggestion that a promising way of understanding that same concept in the context of direct discrimination is by reference to the value underlying this area of law.

Whether this approach provides the best way of understanding the test of unfavourable treatment, however, depends to a very significant extent on whether its adoption would remove the need to rely on a comparator. If it would not do so, then effect would not be given to the statutory purpose underlying the adoption of a test of unfavourable treatment - which, as we have seen, is to remove the need to rely on a comparator. ${ }^{52}$

To ascertain whether the adoption of this approach would remove the need to rely on a comparator, we need to consider what the value underlying prohibitions on discrimination is. What that value is is, of course, disputed. In this Part, we consider three influential accounts, and consider whether they support an understanding of unfavourable treatment that would obviate the need to rely on a comparator.

Obviously, in the context of the present article, it is not possible to consider every account of the value underlying prohibitions on discrimination. What we can do is consider three important accounts and examine whether they support an understanding of unfavourable treatment according to which the need to rely on a comparator can be dispensed with. The accounts we discuss - those of John Gardner, Sandra Fredman and Sophia Moreau - are all influential in their own right, and together offer a broad cross-section of views about the value underlying prohibitions on discrimination.

Before commencing, we should emphasise that Gardner, Fredman and Moreau each offers an account of the value underlying prohibitions on discrimination, not an account of unfavourable treatment. Nor are they necessarily committed to understanding the test of unfavourable treatment in light of their account of the value underlying prohibitions on discrimination more generally. Our concerns, therefore, may diverge from theirs, since we are interested in ascertaining what understanding of unfavourable treatment emerges if we understand that concept in light of their accounts. That said, we think that each of these accounts of the value underlying prohibitions on discrimination offers a distinctive way of

\footnotetext{
52 Though again recall our earlier point that the legislative purpose is not simply to eliminate the need to consider a comparator but to do this by introducing a test of unfavourable treatment.
} 
understanding the test of unfavourable treatment in the context of prohibitions on direct discrimination. We seek to show this below.

\section{i) John Gardner}

According to Gardner, anti-discrimination law is concerned with matters of justice. $\mathrm{He}$ characterises reasons of justice as 'reasons for or against altering someone's relative position'. ${ }^{53}$ Accordingly, on his view, anti-discrimination law is fundamentally concerned with people's relative positions - ie with how they should be treated relative to other people. ${ }^{54}$

More precisely, for Gardner, anti-discrimination law is fundamentally concerned with distributive justice. Gardner understands distributive justice in terms of the contrast with corrective justice. Corrective justice is concerned with 'restoring the relative positions of two or more people (or groups of people) to those which obtained before, or which would have obtained apart from, some action or series of actions taken by one or other of those people (or groups of people), ${ }^{55}$ By contrast, distributive justice is concerned with 'changing the relative positions of people (or groups of people) other than by restoring them to such a status quo ante or status quo alter'. 56

Gardner acknowledges that, if there has been discriminatory treatment, then the discriminator owes a duty of corrective justice to restore the person discriminated against to the position they were in before the occurrence of the discriminatory treatment, or to the position they would have been in had it not been for the discriminatory treatment (eg by way of paying compensation). ${ }^{57}$ However, the primary duties imposed by discrimination law are not these duties of corrective justice but, rather, duties not to discriminate in the first place. ${ }^{58}$ Moreover, someone owes a duty not to discriminate, not because they have committed some past wrong

\footnotetext{
53 John Gardner, 'Discrimination as Injustice' (1996) 16 Oxford Journal of Legal Studies 353, 353

('Discrimination as Injustice').

${ }^{54}$ In presenting Gardner's views, we focus on 'Discrimination as Injustice', which presents his most developed position with regard to why discrimination is wrong. In this piece, he also carefully distinguishes the question of why discrimination is wrong from the further question of why the State is entitled to intervene to redress that wrong. Our concern is with the former question, whereas Gardner's later work on the role that autonomy plays in discrimination law is primarily concerned with the latter question: see, eg, John Gardner, 'On the Ground of Her Sex(uality)' (1998) 18 Oxford Journal of Legal Studies 167.

55 Gardner, above n 53, 355.

${ }^{56}$ Ibid 355-357.

57 Ibid 355.

${ }^{58}$ Ibid.
} 
of a sort that might give rise to a duty of corrective justice, but rather because they owe a duty not to allocate resources or opportunities on the basis of anyone's protected attributes. That is to say, they owe a duty of distributive justice. ${ }^{59}$

We can use Gardner's account of the value underlying anti-discrimination law to give content to the concept of unfavourable treatment. On this approach, unfavourable treatment is to be equated with (distributively) unjust treatment. Ascertaining whether there has been unfavourable treatment would, therefore, require a consideration of whether there has been an inappropriate allocation of resources and opportunities on the basis of the complainant's protected attribute - or, in other words, whether the complainant has received the right allocation relative to what others have received.

One advantage of this approach is that it does not suffer from the over-inclusiveness problem that bedevils the setback to interests approach. What makes the setback to interests approach over-inclusive is that the mere fact that one person's interests have been adversely affected by certain treatment is sufficient to establish that the treatment is unfavourable. By contrast, the fact that one person's interests have been adversely affected by certain treatment is not sufficient to establish that the treatment is unjust. As Gardner defines it, justice is concerned with what the relative positions of different individuals or groups should be, and so requires attention to be paid to the interests of all the relevant individuals or groups.

However, a serious disadvantage of using Gardner's account to give content to the concept of unfavourable treatment (as that concept is used in the legislative materials referred to in Part I above) is that it entails that ascertaining whether there is unfavourable treatment requires the use of a comparator in all cases. This follows from Gardner's claim that discrimination law is concerned with matters of justice and that justice is concerned with the relative positions of different people - in this context, with comparing the treatment accorded to the complainant and the treatment that was, or would have been, accorded to a comparator.

Moreover, this claim - and, in particular, the reference to people's relative positions - is crucial to Gardner's account of justice. Gardner points out that, if A is torturing B, this provides a reason for altering B's position (so that he is no longer being tortured). But he contends that this is not primarily a reason of justice. The fundamental problem is not that $\mathrm{B}$ is being tortured while other people are not being tortured. Rather, it is simply that B is being

${ }^{59}$ Ibid 367. 
tortured (and hence being treated inhumanely). ${ }^{60}$ Thus, on Gardner's account, recognising the comparative nature of considerations of justice is crucial to understanding the difference between the value of justice and other values (such as the value of humane treatment).

The conclusion that a comparator plays a central role on Gardner's account is confirmed by his statement that:

The primary duties of the law relating to sex and race discrimination are duties to treat people in certain ways defined by reference to the way that others are treated.

As the very name 'discrimination' implies, they are duties essentially concerned with peoples' relative positions. ${ }^{61}$

Thus, if we understand the concept of unfavourable treatment in light of Gardner's account of the value underlying anti-discrimination law, employing a test of unfavourable treatment will not avoid the need to rely on a comparator when determining whether the harm element of a claim in direct discrimination is made out. ${ }^{62}$

\section{ii) Sandra Fredman}

Let us now turn to consider Sandra Fredman's account of the value underlying prohibitions on discrimination. Does this account provide a way of understanding the test of unfavourable treatment such that use of this test avoids the need to rely on a comparator?

Fredman claims that the core value underlying anti-discrimination law is equality. One might think that equality, like justice, is a comparative notion. However, Fredman offers an account of equality according to which this is only partly true. The crux of her account is the claim that equality is 'multi-dimensional' . ${ }^{63}$ Fredman identifies four 'dimensions' of equality: the redistributive dimension; the recognition dimension (concerned with promoting respect and dignity); the transformative dimension (concerned with accommodating difference and

\footnotetext{
${ }^{60}$ Ibid 353.

${ }^{61}$ Ibid 355 (emphasis added). See also ibid ('comparisons between people are of the essence in defining antidiscrimination law's primary duties').

${ }^{62}$ Gardner's account is by no means the only account of the value underlying prohibitions on discrimination that has the implication that reliance on a comparator is essential to ascertaining whether there is direct discrimination. Other examples include Deborah Hellmann, Why is Discrimination Wrong? (Harvard University Press, 2008) and Patrick Shin, 'The Substantive Principle of Equal Treatment' (2009) 15 Legal Theory 149. (But see Sophia Moreau, 'In Defense of a Liberty-based Account of Discrimination' in Deborah Hellman and Sophia Moreau (eds), Philosophical Foundations of Discrimination Law (Oxford University Press, 2013) 71, 75. Moreau contests Hellman's claim that Hellman's theory is comparative in the relevant sense.)

${ }^{63}$ Fredman, above n 2, 25.
} 
achieving structural change); and the participation dimension (concerned with promoting social inclusion and political voice). ${ }^{64}$

Some of these dimensions are clearly not comparative. For example, dignity is not a comparative notion. A can infringe B's dignity, quite irrespective of how A treats C, D or E. Fredman draws on this point to argue that the value of equality can be infringed even if there is no obvious comparator. ${ }^{65}$ One might conclude, therefore, that, if we take unfavourable treatment to mean unequal treatment, and understand unequal treatment in light of Fredman's account of equality, there is no need to use a comparator to assess whether there has been unfavourable treatment.

Such a conclusion would, however, be too hasty. Fredman allows that one concern of antidiscrimination law is distributive justice. ${ }^{66}$ This is reflected in her recognition of the redistributive dimension to the value of equality which she claims underlies antidiscrimination law. As we saw in the context of our discussion of Gardner, distributive justice is an essentially comparative notion. Of course, it is possible that Fredman has in mind a conception of distributive justice that is different from Gardner's. However, Fredman's discussion of the redistributive dimension of equality makes it clear that she is employing a conception of distributive justice that is essentially comparative. She states, when discussing the redistributive dimension, that equality 'aims to break the cycle of disadvantage associated with status or out-groups. ${ }^{67}$ Disadvantage here is clearly a comparative notion - an 'outgroup' can only be characterised as an 'out-group' by contrast with an 'in-group'. Similarly, Fredman states (again, when discussing the redistributive dimension) that her notion of equality 'focuses on the group which has suffered disadvantage: women rather than men, black people rather than whites, people with disabilities rather than able-bodied, or gay people, rather than heterosexuals'. ${ }^{68}$

Thus, to the extent that direct discrimination is concerned with distributive justice, it seems that the use of the comparator will be necessary to ascertain whether there has been unfavourable treatment. ${ }^{69}$ However, whether this is so turns, at least in part, on the extent to

\footnotetext{
${ }^{64}$ Ibid 25-33.

${ }^{65}$ Ibid 22.

${ }^{66}$ Ibid 16.

${ }^{67}$ Ibid 25.

68 Ibid 26.

${ }^{69}$ Fredman regards the adoption of a test of unfavourable treatment in the context of discrimination on the ground of pregnancy, under the Equality Act 2010 (UK), as eliminating the need to rely on a comparator (ibid 170). However, she does not indicate the basis on which she reaches this conclusion. It is possible that she is
} 
which the redistributive dimension would be relevant to claims in direct discrimination were a test of unfavourable treatment to be employed. It is clear that Fredman does not view the redistributive dimension as the most important of the four dimensions of equality in the context of direct discrimination. She states that the 'primary contribution' that direct discrimination makes to advancing her multi-dimensional concept of equality 'is in relation to the recognition dimension'. ${ }^{70}$ This is most naturally read as suggesting that direct discrimination also advances the other dimensions of equality - including the redistributive dimension - but the role that it plays in doing so is secondary to the role it plays in advancing the recognition dimension (which, as we have seen, is not comparative in nature).

However, soon after stating that direct discrimination is primarily concerned with advancing the recognition dimension, Fredman makes the stronger claim that ' $[\mathrm{t}]$ he remaining dimensions of equality are out of the range of direct discrimination'. ${ }^{71}$ This may suggest that Fredman does not regard the redistributive dimension as playing any role at all in the context of direct discrimination.

The ambiguity is important, for our purposes, because it gives rise to uncertainty about whether the comparator is needed if one adopts the value-based approach to understanding the test of unfavourable treatment (in circumstances where one has accepted Fredman's account of what the relevant value is). If the redistributive dimension has a role to play in the context of direct discrimination, even if it is a secondary role, then - given that the redistributive dimension is comparative - there will be a need to rely upon a comparator when applying the test of unfavourable treatment. By contrast, if the redistributive dimension is 'out of the range' of direct discrimination, then the fact that the redistributive dimension is comparative is irrelevant for the purposes of understanding the test of unfavourable treatment in the context of direct discrimination.

However, any claim that the redistributive dimension has no role whatsoever to play in the context of direct discrimination would seem to be overstated, even on Fredman's own account. Perhaps the redistributive dimension is not often relevant, but Fredman herself

presupposing something like the setback to interests approach, despite the problem with that approach identified in Part II above. If this were so, her conclusion would have no bearing on the question of whether adopting a test of unfavourable treatment removes the need to rely on a comparator where that test is understood in light of the value-based approach.

${ }^{70}$ Ibid 176.

${ }^{71}$ Ibid 177 (emphasis added). It should be noted that, immediately after making this stronger claim, Fredman appears to retreat from it, stating that the symmetry underlying direct discrimination 'makes it difficult to advance the redistributive dimension' (emphasis added). 
claims that it is relevant in cases involving 'underpayment for work of equal value, or limitations on access to credit, property, or other similar resources'. ${ }^{72}$ At least some such cases would properly be regarded as involving claims in direct discrimination.

Moreover, Fredman suggests that the notion of disadvantage that underpins the redistributive dimension should not be understood as being confined to such 'maldistribution of resources'. ${ }^{73}$ Rather, one's understanding of the notion of disadvantage 'needs also to take on board the constraints which power structures impose on individuals because of their status.' 74 For example, women whose role is confined to the private sphere are, Fredman says, disadvantaged, even if they are materially well-off. This is significant for our purposes because, the broader the understanding of disadvantage, the greater the scope for the redistributive dimension to play a role. Thus, Fredman's suggestion that the notion of disadvantage is not confined to 'maldistribution of resources' makes it less plausible to interpret her as claiming that this dimension plays no role whatsoever in the context of direct discrimination.

Finally, it is hard to deny that prohibitions on direct discrimination, if properly enforced, assist in tackling distributive injustice. Obviously, even if they are rigorously enforced, such prohibitions are insufficient to eliminate distributive injustices. However, they do ensure that members of certain disadvantaged groups cannot lawfully be denied important resources and opportunities simply because of their membership of such groups. Thus, prohibitions on direct discrimination do advance the redistributive dimension to some extent, even if the recognition dimension has a greater role to play in this area of law.

For these reasons, we do not think that Fredman should be read as claiming that the redistributive dimension has no role whatsoever to play in the context of direct discrimination. However, this still leaves open two possible readings of her position. On the first, the redistributive dimension is generally (perhaps even always) relevant to claims in direct discrimination, but as a secondary consideration. (This fits with her suggestion that the recognition dimension is primary.) On the second, the redistributive dimension is generally

\footnotetext{
72 Ibid 26.

${ }^{73}$ Ibid 27.

74 Ibid.
} 
not relevant, but will be in certain cases, including those involving 'access to credit or property, or other similar resources'. ${ }^{75}$

The crucial point for our purposes is that, on either reading, there will at least sometimes be a need to rely on a comparator in order to establish that there has been unfavourable treatment (if the test of unfavourable treatment is understood in light of the value which Fredman claims underlies prohibitions on discrimination). This is because, on Fredman's account, the redistributive dimension of equality will, at least sometimes, be relevant to claims in direct discrimination and that dimension is essentially comparative. Thus, the value-based approach, when interpreted in light of Fredman's account of the value underlying prohibitions on discrimination, does not fully succeed in eliminating the need to rely on a comparator.

Nevertheless, for those hoping that the test of unfavourable treatment will eliminate the need to rely on a comparator, an understanding of unfavourable treatment based on Fredman's account may be significantly more attractive than an understanding based on Gardner's account. Even if consideration of a comparator is always necessary on Fredman's account (because the redistributive dimension is always relevant), it is only one relevant factor among several (because the redistributive dimension is only one of four dimensions of equality). Moreover, if prohibitions on direct discrimination are primarily concerned with the recognition dimension, then the role played by the redistributive dimension (and therefore the comparator) will be secondary. The less the significance that is attached to the comparator for the purpose of determining whether there is unfavourable treatment, the less pressing the problems with the comparator are likely to be. ${ }^{76}$ Moreover, in cases where reliance on a comparator is particularly problematic, there may be scope to attach less weight to the redistributive dimension than in other cases.

Similarly, if the redistributive dimension is generally not relevant in the context of direct discrimination, then adopting the value-based approach as understood in light of Fredman's account eliminates the need to rely on a comparator in most cases. It therefore significantly ameliorates the problems associated with the use of a comparator, though it is true that there

\footnotetext{
${ }^{75}$ Ibid 26.

${ }^{76}$ In this connection, see Goldberg's suggestion that employing a comparator should be one strategy among several for determining whether there has been discrimination, and that the difficulties involved in using a comparator would be reduced if this suggestion were to be adopted: Suzanne B Goldberg, 'Discrimination by Comparison' (2011) 120 Yale Law Journal 728, 808-9. It is also worth noting that Fredman appears to adopt an analogous stance towards the recognition dimension, stating that 'locating dignity as one dimension of a multifaceted notion of equality permits us to buttress it in such a way as to utilise its strengths while addressing its weaknesses': Fredman, above n 2, 29.
} 
will be some cases where those problems still arise (because there will be some cases, such as those involving access to credit or property, where the redistributive dimension is relevant and so recourse to a comparator is needed).

\section{iii) Sophia Moreau}

A third account of the value underlying prohibitions on discrimination is provided by Sophia Moreau. Moreau contends that the interest protected by discrimination law is 'our interest in a set of ... deliberative freedoms: that is, freedoms to have our decisions about how to live insulated from the effects of normatively extraneous features of us, such as our skin color or gender.' 77

For Moreau, it is crucial that people are free to deliberate about how to live their lives and to act on those deliberations. As she puts it, '[i]n a liberal society, each person is entitled to decide for herself what she values, and how she is going to live in light of these values. ${ }^{78}$ For instance, it is important that one be free to decide for oneself which career one wants to pursue. One does not possess such freedom, however, if one has to take account of one's gender or race when choosing a career. ${ }^{79}$ These are 'normatively extraneous' in the sense that we should not have to take account of them when making decisions about how we should live our lives. ${ }^{80}$ However, if one would be exposed to sexual or racial discrimination in a particular workplace, one would have to take account of one's gender or race when deciding whether to seek employment, or remain employed, in that workplace. The role of discrimination law, according to Moreau, is to prevent this sort of infringement of one's deliberative freedoms, to ensure that one really can decide what career to pursue (and make

\footnotetext{
${ }^{77}$ Sophia Moreau, 'What is Discrimination?' (2010) 38 Philosophy and Public Affairs 143, 147. (This article contains the fullest exposition of Moreau's position, but see also Moreau, above $\mathrm{n} 62$.)

${ }_{78}^{78}$ Moreau, above $\mathrm{n} 77,147$.

${ }^{79}$ On Moreau's account, gender and race are not the only normatively extraneous traits. Many, perhaps all, of the standard protected attributes will be normatively extraneous, as may be further traits, such as physical appearance (ibid 157-8). However, for ease of exposition, we will use race and gender as our examples in this part of the paper.

${ }^{80}$ Ibid 149. Moreau emphasizes that one's race or gender may be an important part of one's self-identity and so one may wish to take into account one's race or gender when making a broad range of decisions. Her point is that one should not have to take account of such matters; they should not be costs attaching to particular choices that one might make.
} 
other life choices as well) without having to take into account other people's reaction to one's normatively extraneous features. ${ }^{81}$

Again, this account of the value underlying discrimination law could be used to shed light on the test of unfavourable treatment in the harm element of a claim in direct discrimination. The idea would be that unfavourable treatment is treatment which infringes our deliberative freedoms. Moreau suggests that treatment infringes our deliberative freedoms where it involves denying opportunities to us because of our normatively extraneous features. ${ }^{82}$ One consequence, where someone is denied an opportunity based on her race or gender, is that she must take account of her race or gender in assessing what opportunities are available to her. She is, therefore, no longer free to make decisions about how to live her life without having to consider her normatively extraneous features.

It might be thought that this provides an understanding of unfavourable treatment that avoids any need to rely on a comparator. Whether or not a person is denied an opportunity, based on their normatively extraneous features, depends on how they have been treated, not on how other people have been treated. (Though consideration of a comparator may be useful in establishing that someone has been denied an opportunity based on their normatively extraneous features, a point to which we will return shortly.)

However, there are two aspects of Moreau's approach that might seem inconsistent with this conclusion. Firstly, she states that everyone's deliberative freedoms should be protected to roughly the same extent. ${ }^{83}$ This appears to introduce a comparative aspect into her account, since it seems to suggest that the adequacy of the protection accorded to a person's deliberative freedoms must be assessed by reference to the level of protection accorded to other people's deliberative freedoms. However, Moreau goes on to make it clear that this is not what she has in mind. As she says,

each of us is entitled to certain deliberative freedoms, and our entitlement is not dependent on whether other people have been granted these freedoms. On this view, then, although it is true that we are all entitled to these deliberative freedoms to an extent roughly equal to others, this is only because each of us has an independent

\footnotetext{
${ }^{81}$ Moreau denies that discrimination law is concerned only with important choices. On her view, we should also be able to choose to which restaurant to go, free from any pressure arising from our normatively extraneous features (ibid 152).

${ }^{82}$ Ibid $147,155$.

83 Ibid 160 .
} 
entitlement to the freedoms in question. Our entitlement is not contingent upon whether others also have the relevant deliberative freedoms [.] ${ }^{84}$

Secondly, when discussing how her approach works in the context of direct discrimination, Moreau states that the prohibition on direct discrimination ensures that normatively extraneous traits will not 'be used to single us out for unfavourable treatment' ${ }^{85}$. This reference to 'singl[ing] us out' might be thought to suggest that a comparator is needed, since it implies that the concern is that we are being treated differently from those who do not possess our normatively extraneous trait.

Nevertheless, we think that the better interpretation of Moreau's position is that use of a comparator is not an essential feature of the position. ${ }^{86}$ This is partly because the passage quoted above ${ }^{87}$ suggests that Moreau's considered view is that what treatment should be accorded to us is not dependent on the treatment that has been accorded to others. It is also partly because there appears to be no need to make reliance on a comparator an essential feature of the position. As mentioned above, we may be able to tell that someone has been denied an opportunity based on a normatively extraneous feature of theirs without needing to consider how anyone else has been treated. ${ }^{88}$

That said, the comparator may still play an evidential role on Moreau's account. Moreau points out that 'it is often through a comparison with [other people who already have the relevant deliberative freedom] that claimants come to realize that they lack a particular deliberative freedom. ${ }^{89}$ If a claimant identifies discrimination in this way, they may wish to lead evidence concerning the possession of that deliberative freedom by other people, in order to persuade the court that the claimant has in fact been discriminated against.

\footnotetext{
84 Ibid 174.

${ }^{85}$ Ibid 155 (emphasis in original).

${ }^{86}$ The statement in the text may require qualification. The use of a comparator is not an essential feature of Moreau's account, but that account seeks to capture only the 'personal wrong' committed by a discriminator against the complainant (ibid 145-6). Moreau allows that, in addition to this personal wrong, there may also be 'harms or injustices ... suffered by each of the groups marked out by the grounds of discrimination' (at 178). She further allows that some discrimination laws may be designed not only to address the personal wrong to individual complainants, but also to 'rectify injustices suffered by these groups' (at 178). If this is true of prohibitions on direct discrimination, then a comparator may have an essential role to play in the context of such prohibitions after all (on the plausible assumption that the identification of injustices suffered by certain groups requires a comparison between the treatment accorded to members of those groups and the treatment accorded to members of advantaged groups). However, since Moreau does not offer a considered view as to whether prohibitions on direct discrimination have this additional aim, we shall leave the possibility to one side.

87 See the text accompanying above $\mathrm{n} 84$.

88 This interpretation appears to be confirmed by Moreau, above $\mathrm{n} 62,74$.

${ }^{89}$ Moreau, above n 77, 174.
} 
Thus, adducing information about comparators may assist complainants in proving unfavourable treatment, even if the test of unfavourable treatment is understood in light of Moreau's account. However, leading evidence concerning comparators would be only one way in which the complainant might seek to make their case. Importantly, there would be no compulsion on complainants to rely on such evidence (unlike on Gardner's account, where consideration of the way in which a comparator was, or would have been, treated is essential to establishing unfavourable treatment, since it goes to the heart of whether there is distributive injustice). ${ }^{90}$ And, on Moreau's account, even where the complainant does rely on evidence about a comparator, this may be only one piece of evidence among several, and the weight that it is given could vary depending on the extent to which the sorts of problems with the use of a comparator that were identified in the Introduction manifest in the particular case.

This means that Moreau's account of the value underlying prohibitions on discrimination, when used to understand the test of unfavourable treatment, is well suited to achieving the purpose behind the adoption of that test. As we have seen, that purpose is to remove the need to rely on a comparator by adopting a test of unfavourable treatment.

\section{iv) Choosing between the accounts?}

The preceding discussion shows that whether the value-based approach eliminates the need to rely on a comparator depends on which of the rival accounts of the value underlying prohibitions on discrimination is correct. If Gardner's account is correct, then understanding the test of unfavourable treatment in terms of the value underlying prohibitions on discrimination will not eliminate the need to rely on a comparator. On the contrary, consideration of a comparator will be necessary in every case. Alternatively, if Fredman's account is correct, it will be necessary to consider the comparator in at least some cases, although it may not be necessary to do so in all cases (or, on the alternative interpretation of Fredman, it may always be necessary to consider the comparator, but the comparator is only one of several factors relevant to whether the complainant was treated unfavourably). Finally, if Moreau's account is correct, then moving to a test of unfavourable treatment, and understanding that test in light of the value underlying prohibitions on discrimination, will succeed in eliminating the need to rely on the comparator.

\footnotetext{
90 Similarly, on Fredman's account, to the extent that direct discrimination is concerned with the redistributive dimension of equality, consideration of a comparator is essential, not merely a useful piece of evidence.
} 
Thus, the question of how to choose between the competing accounts of the value underlying prohibitions on discrimination becomes crucial to a resolution of our central question: does the use of a test of unfavourable treatment remove the need to rely on a comparator? One might look to the legislative materials with which we are concerned to see if one of the competing accounts fits better with those materials than the others. The objects provisions in some of those materials might be thought to support the view that the value underlying prohibitions on discrimination in the relevant jurisdictions is something akin to Fredman's account of equality. For example, the objects provision in cl 3(1) of the Human Rights and Anti-Discrimination Bill 2012 (Cth) states:

The objects of this Act are as follows:

(d) to promote recognition and respect within the community for:

(i) the principle of equality (including both formal and substantive equality); and

(ii) the inherent dignity of all people;

Similarly, the objectives provision in s 3 of the Equal Opportunity Act 2010 (Vic) states:

The objects of this Act are-

...

(b) to further promote and protect the right to equality set out in the Charter of Human Rights and Responsibilities;

(d) to promote and facilitate the progressive realisation of equality, as far as reasonably practicable, by recognising that-

(i) discrimination can cause social and economic disadvantage and that access to opportunities is not equitably distributed throughout society;

(ii) equal application of a rule to different groups can have unequal results or outcomes;

It might be thought that the emphasis in these provisions on promoting equality fits neatly with Fredman's claim that the value underlying prohibitions on discrimination is equality. The reference to dignity in the Commonwealth Bill might also be thought to fit with Fredman's claim that the concept of equality has a 'recognition dimension' that is concerned with promoting respect and dignity.

However, one should not be too quick to conclude that something like Fredman's account of the value underlying prohibitions on discrimination is reflected in these legislative materials. For one thing, the Commonwealth Bill refers to equality and dignity as separate considerations, whereas Fredman treats dignity as one aspect of equality. More importantly, 
the concept of equality is a contested one, ${ }^{91}$ and so we cannot assume that the conception or understanding of equality employed in the legislative materials is the same as that employed in Fredman's account. This is particularly so, given that Fredman provides a very specific and technical account of what she means by equality, whereas the references to equality in the legislative materials form part of a very general characterisation of the purposes of those materials.

Indeed, we cannot rule out the possibility that the objects provisions mentioned above are also compatible with Gardner's and Moreau's accounts of the value underlying the prohibition on discrimination. While neither Gardner nor Moreau claims that the value underlying prohibitions on discrimination is equality, a certain type of equality would be achieved if either of their accounts were successfully implemented. We saw above that Moreau explicitly draws her readers' attention to this fact, pointing out that everyone is entitled to the deliberative freedoms to a roughly equal extent, while denying that one's entitlement to those freedoms is contingent on whether other people also have them. Thus, it would be incautious to assume, on the basis of the very general reference to equality in the objects provisions referred to above, that these legislative materials serve to exclude Moreau's account as a viable account of the value underlying the prohibitions on discrimination that they enact. Similarly, it is open to Gardner to claim that a form of equality would be achieved through the consistent application of the principles of distributive justice that he claims underlie prohibitions on discrimination. ${ }^{92}$

Thus, the objects provisions in the legislative materials with which we are concerned do not provide much assistance in choosing between the competing accounts of the value underlying prohibitions on discrimination. There is, however, a different basis on which one may make that choice, which may appear attractive. It might be argued that Moreau's account is preferable because it not only avoids the over-inclusiveness problem, but (unlike Fredman's and Gardner's accounts) also ensures that there is no need to consider a comparator for the purposes of the harm element. In other words, it is the only one of the three accounts which achieves the purpose behind introducing a test of unfavourable treatment - namely, to eliminate the need to rely on a comparator by introducing a test of unfavourable treatment.

\footnotetext{
${ }^{91}$ See, eg, Stefan Gosepath, 'Equality', The Stanford Encyclopedia of Philosophy (Spring 2011 Edition), Edward N. Zalta (ed.), URL $=<$ http://plato.stanford.edu/archives/spr2011/entries/equality/>.

${ }^{92}$ In this respect, see Joseph Raz, The Morality of Freedom (Clarendon Press, 1986) ch 9 (arguing that 'equality' is often used to refer to principles that achieve equal treatment simply as a by-product of the general application of those principles).
} 
However, one cannot choose between the three accounts on this basis alone. Each of those accounts is meant to identify the value underlying all of discrimination law. This value is meant to underpin not merely the test of unfavourable treatment but also other features of discrimination law. With regard to direct discrimination, these include the attributes that are protected by prohibitions on discrimination (such as sex and race), ${ }^{93}$ the spheres of activity in which discrimination is illegal (such as employment and education), and the causation element of a claim in direct discrimination. Moreover, these accounts are meant to be applicable not only to direct discrimination, but also to indirect discrimination. ${ }^{94}$ This means that these accounts must also be judged by reference to their ability to explain the key elements of prohibitions on indirect discrimination.

Thus, the fact that Moreau's account best fits with the purpose behind introducing the test of unfavourable treatment is not sufficient to show that it should be preferred to Gardner's and Fredman's accounts. It is, of course, a point in its favour. However, this is only one consideration among many. Whether Moreau's account should ultimately be preferred depends on whether it provides the best account of discrimination law in general. To show that it does so would require showing that it also best fits with other features of discrimination law, including those referred to in the previous paragraph.

To sum up, the legislative materials do not provide an adequate basis for choosing between the competing accounts of the value underlying prohibitions on discrimination. Nor can we choose between them by considering only which account best fits with the purpose behind introducing a test of unfavourable treatment. Rather, the choice between the competing accounts must be made by reference to which account best explains all of the many different aspects of discrimination law.

This means that choosing between the competing accounts of the value underlying prohibitions on discrimination is not a task we can undertake here. A comparison of the ability of each account to explain all of the aspects of discrimination law referred to above would require, at the very least, a separate article of its own. Nevertheless, this article has, we hope, advanced the understanding of whether adopting a test of unfavourable treatment will obviate the need to rely on a comparator. Among other things, we have sought to show how understanding that test in light of different accounts of the value underlying prohibitions on

\footnotetext{
${ }^{93}$ In this respect, it is worth noting that Moreau's account may support a somewhat different list of attributes from those typically protected in discrimination law: see above $\mathrm{n} 79$.

${ }^{94}$ See Gardner, above n 53, 355; Fredman, above n 2, 181-182; Moreau, above n 77, 155.
} 
discrimination produces different implications for the role, if any, that the comparator would play under a test of unfavourable treatment.

\section{Conclusion}

In this article, we have subjected to critical scrutiny the widely accepted view that use of a test of unfavourable treatment avoids the need to rely on a comparator with regard to the harm element of a claim of direct discrimination. We have seen that whether that view is correct depends on how the test of unfavourable treatment should be understood. We have argued that one influential understanding of that test - which focuses on whether the treatment was adverse to the complainant's interests - is unacceptable by virtue of being radically over-inclusive. We then argued that an alternative understanding - which focuses on whether the treatment disappointed the complainant's reasonable expectations - avoids this problem, but either fails to eliminate the need to rely on a comparator or else collapses into the third understanding we considered, which we labelled the 'value-based' approach.

We contended that the value-based approach also avoids the problem of over-inclusiveness, but that whether it eliminates the need to rely on a comparator depends on which account of the value underlying prohibitions on discrimination is preferable. To support this contention, we examined three influential accounts of the value underlying prohibitions on discrimination, and explored their implications for the question of whether reliance on a test of unfavourable treatment obviates the need to consider a comparator. We showed that the implications of these three accounts for our central question are very different. We then considered how the choice between these three accounts should be made. We argued that appeal to objects clauses in the relevant legislation is insufficient to show that one account is preferable, and also that the choice cannot be made solely on the basis of which account best achieves the purpose behind the introduction of a test of unfavourable treatment. Rather, the choice must be made by ascertaining which account best fits with a broad range of features of discrimination law, of which the test of unfavourable treatment is just one. Moreover, it is only after that choice is made that the full implications of adopting a test of unfavourable treatment can be ascertained. 


\section{University Library}

\section{- M M I N E R VA A gateway to Melbourne's research publications}

Minerva Access is the Institutional Repository of The University of Melbourne

Author/s:

Smith, D;Campbell, C

Title:

Direct Discrimination without a Comparator? Moving to a Test of Unfavourable Treatment

Date:

2015

Citation:

Smith, D. \& Campbell, C. (2015). Direct Discrimination without a Comparator? Moving to a Test of Unfavourable Treatment. Federal Law Review, 43 (1), pp.91-118

Persistent Link:

http://hdl.handle.net/11343/241642 